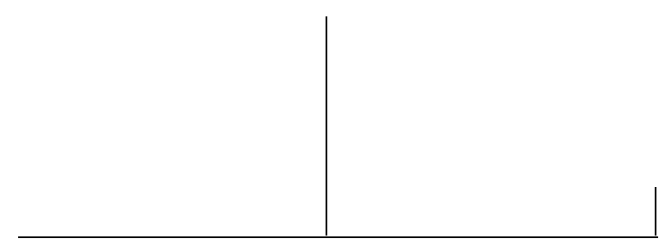

Rev. Latinoam. Psicopat. Fund., São Paulo, v. 14, n. 4, p. 711-720, dezembro 2011

\title{
Lembrar para esquecer: a memória da dor no luto e na consolação*
}

Paulo José Carvalho da Silva

Este artigo retoma discursos da antiga tradição da consolação e outras variantes da medicina da alma para examinar a dimensão da memória especificamente no trabalho do luto. Em particular, analisa como a memória era definida, principalmente qual era a sua relação com a origem e a permanência das dores da alma e, por conseguinte, qual era a sua função nas práticas terapêuticas da primeira modernidade.

Palavras-chave: Memória, males da alma, luto, consolação, psicanálise

* Pesquisa realizada com auxílio Bolsa de Produtividade do Conselho Nacional de Desenvolvimento Científico e Tecnológico - CNPq (Brasília, DF, Brasil). 
Ao contrário do senso comum, que afirma que o tempo cura todos os males, Freud supõe um trabalho psíquico no luto: é necessário pronunciar interiormente a morte do que se foi. Assim, muito distinto de um esquecimento passivo, o luto é um esforço que exige lembrar para esquecer: "Cada uma das lembranças e expectativas em que a libido se achava ligada ao objeto é enfocada e superinvestida, e em cada uma sucede o desligamento da libido" (Freud, 1917, p. 174). Ora, tal empreitada não se faz sem dor, inclusive porque, como bem lembra Manoel Berlinck (2011), o luto freudiano se faz na contracorrente da exigência de imortalidade.

Além do mais, no inconsciente não há alteração do evento psíquico pelo transcurso do tempo. Aliás, o neurótico sente-se ameaçado por perigos atemporais, renovados, repetidos em sua história. Em "Inibição, sintoma e angústia", Freud (1925-26), lembra que, ao longo da vida, cada uma das condições de dor tem um tempo e desaparece com ele. Consideramos normal que uma menina de quatro anos chore desconsoladamente porque sua boneca está quebrada; de seis, porque sua mestra a repreendeu; de 16, porque foi preterida por seu namorado; uma mulher de 25 anos, porque seu filho está morto. Estranharíamos, porém, que uma mulher adulta chorasse pela perda de uma boneca. No entanto, é essa a conduta dos neuróticos: mesmo tendo condições para satisfazer suas necessidades e se proteger, vivem como se subsistissem todas as antigas situações de dor e de perigo, mantendo, assim, todas as condições anteriores.

Nesta mesma seção, Marina Massimi (2010) abordou a história do dinamismo da memória e como seu poder de fazer presente o que está ausente fora tratado em analogia à digestão, relacionando- a a um dado processo de incorporação. Por sua vez, este artigo retoma selecionados discursos da antiga tradição da consolação e outras variantes da medicina da alma para discutir a dimensão da 
memória especificamente no trabalho do luto. A reconstrução histórica do conceito de memória prioriza sua relação com a origem e a permanência das dores da alma e, por conseguinte, focaliza qual era a sua função na medicina da alma e na consolação.

\section{Consolatio et recordatio}

A dimensão temporal da dor e a função da memória aparecem nos discursos consolatórios desde os primeiros formadores do gênero. Conforme Sêneca (4 a.C-65), em Consolação a Márcia (Ad Marciam de Consolatione), justamente Octávia, que jamais supera o luto, recusa lembrar-se da vida de seu filho, preferindo fixar-se em sua morte. Já Lívia opta pelo gozo da memória, não pelo gozo da dor. Segundo o filósofo, ela não pôde presenciar os últimos momentos de seu filho, mas jamais deixou de falar sobre ele ou contemplar suas imagens.

Nas últimas exortações da Consolação a Polibio, Sêneca sugere a esse ministro do imperador Claudio, enlutado pela perda de um irmão mais novo, que ele escreva as memórias do irmão porque a melhor maneira de imortalizá-lo seria por meio de uma obra do espírito: "mais vale imortalizá-lo por seu talento durável do que lhe consagrar lágrimas estéreis" (Sêneca, XVIII, 2, 1998, p. 98; tradução nossa). Não se deve dar uma mão forte à própria dor. Por essa razão, é permitido emocionar-se, mas não se deve deixar-se perturbar pela emoção. Para tanto, concorre o cultivo da memória do vivo: "Trate de desejar que a lembrança de seu irmão venha a todo o momento ao seu espírito, de falar frequentemente de seu irmão, de ter sua imagem sempre frente aos olhos" (Sêneca, XVIII, 7, 1998, p. 99; tradução nossa). Entretanto, Sêneca também adverte que essa estratégia somente terá o efeito esperado se Polibio souber tornar essa lembrança mais agradável do que dolorosa. Nesse sentido, é necessário, mais do que nunca, fixar-se nas qualidades e satisfações gozadas em vida. Ele prossegue recomendando: "Lembre-se de sua delicadeza, lembre-se de sua habilidade nos negócios, de seu zelo nas ações, de sua fidelidade à palavra empenhada. Conte aos outros todas as suas proposições e todos os seus atos, repita-os a si mesmo" (Sêneca, XVIII, 8, 1998, p. 99; tradução nossa).

A mesma dinâmica de escolha da memória da vida enquanto remédio consolatório contra a dor da perda aparece em Plutarco (45-120). Em Consolação a Apolonius, como argumento consolatório contra a prolongação do luto, Plutarco afirma que um homem virtuoso, após a sua morte, não merece o luto, mas uma lembrança gloriosa. É, portanto, prestando homenagens e cultivando a sua memória que se deve demonstrar o afeto pelos que se foram. 


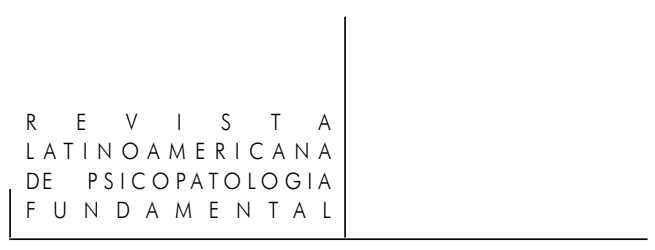

Logo no início da Consolação a minha esposa, Plutarco afirma que teme, ao pôr fim ao luto, também pôr fim à memória da filhinha querida. Mas, na realidade, a memória não precisa ser apenas da dor. Entre outros argumentos consolatórios, Plutarco pede à sua esposa que use de sua memória para transportar-se de volta ao tempo antes do nascimento de sua filha. Ao comparar aquele momento com o momento atual, ou seja, como era sua vida antes, eles acabariam por lamentar o próprio nascimento de Timoxena. Mas não é isso que ele quer, pois não deseja apagar a memória da pequena filha. Pelo contrário, ele insiste em concentrar-se na memória dos dois anos de prazer e de contentamento que a Fortuna lhe concedeu na sua companhia.

Dentre os remédios suaves propostos pela personificação da Filosofia no diálogo que compõe a obra A consolação da filosofia, de Boécio (475-525), neste caso, contra sua infelicidade perante sua sorte injusta, figura-se também a lembrança do bem-estar do passado, como as alegrias em família ou as satisfações de sua carreira política.

No âmbito da consolação cristã, o mesmo argumento também comparece, sustentado, por sua vez, nas Sagradas Escrituras, em específico, em Salomão: "Nos dias de aflição não esqueças os dias de bem-estar" (Eclo 11, 27), citado, por exemplo, por Mestre Eckhart (1260-1328), em O livro da divina consolação (Das Buch der göttlichen Tröstung), dedicado a consolar a rainha Isabel da Hungria, que num curto intervalo de tempo perdera o marido, a fortuna e tivera o pai assassinado.

Entretanto, na própria consolatória cristã, recordar também era reputado ser a causa de uma dor renovada e exasperante. Segundo Giuseppe Chiecchi (2005), a posição de Ambrósio (340-397) sobre os efeitos dolorosos da recordatio marca o debate sobre as funções da memória nessa tradição. Para o bispo de Milão, bem como para Jerônimo (348-420), a consolação tardia, após a ferida já ter cicatrizado pelo efeito sedativo do tempo, mais exaspera pela evocação da memória do que propriamente cura.

O mesmo podia valer, entretanto, para a consolação precipitada. Pensava-se que a consolação teria mais chance de ocorrer passado o calor da dor. No preâmbulo da Consolação a minha mãe Helvia, Sêneca escreve que havia pensado em consolá-la antes, mas temia que, contrariando a vivacidade do seu sofrimento, suas consolações irritassem e inflamassem ainda mais a sua dor, pois não há nada mais perigoso, mesmo na enfermidade, que um remédio prematuro.

Silvia Stucchi (2007) explica que o topos do tempo como médico, ou seja, que, no fim, o tempo é o melhor remédio ou, pelo menos, possui efeito aliviador das penas; já era um lugar-comum popular grego, que fora empregado por Sófocles, por exemplo, em suas tragédias. Tal ideia foi amplamente aplicada aos discursos consolatórios desde a Antiguidade até a época moderna. 
Mas isso não significava necessariamente relegar a consolação à passagem do tempo. Chiecchi (2005) lembra que Ambrósio também adverte que a verdadeira consolação, mais do que operar apenas uma sedação da percepção da dor, deveria confortar, promovendo o reconhecimento da inelutabilidade do limite, da finitude do homem.

\section{A memória entre o saber e o sentir}

Os autores da época moderna produziram várias reflexões sobre a memória, não apenas no âmbito da consolação, mas em outros gêneros filosóficos, inclusive retomando-se os antigos e medievais.

Segundo o Da memória e da reminiscência de Aristóteles (Parva Naturalia), $\mathrm{o}$ ato da memória diz respeito a algo que a alma anteriormente escutou, sentiu ou pensou. Como não há pensamento sem imagem, a parte da alma envolvida na memória é a mesma da imaginação. Com base em leituras da psicologia aristotélica, admitia-se, nos séculos XVI e XVII, que a memória é um hábito que retém e representa a espécie (representante ou imagem da coisa), após passado algum tempo, como na experiência do aprendizado. Seus ofícios incluem a reminiscência, que seria quase como ressuscitar as espécies, a ação de replicar ou renovar algo ou, ainda, simplesmente constituir um tesouro.

A arte da memória fazia parte da educação mais refinada da época, como aquela oferecida nos colégios jesuíticos implantados pela Europa. Luce Giard (2008) relata que, quando a rainha Cristina da Suécia visitou o Colégio da Trindade, em Lyon, em 1657, o jovem jesuíta Claude-François Ménestrier exibiu sua memória passando num teste constituído de uma primeira leitura de uma lista de trezentas palavras, bizarras e sem sentido, para, em seguida, recitá-la perfeitamente de frente e de trás. Além da importante função intelectual de constituir e reter um repertório teórico, pensava-se a memória também como a capacidade de possuir um saber prático, voltado para o julgamento das ações sensíveis e cotidianas.

A memória serve, portanto, para a conservação e acesso a imagens e ideias. Mas não só. Ela também se refere ao domínio dos afetos. Embora não entre em detalhes, Mary Carruthers (1990) explica que na cultura medieval a memória estava intimamente relacionada ao campo do desejo. Afinal, as emoções são a matriz das impressões da memória e o desejo move o intelecto, chama à memória, requisito para uma compreensão maior.

O rei filósofo português Dom Duarte (1391-1438), em seu Leal Conselheiro, escreve que há uma memória que pertence à alma racional, aquela da arte 


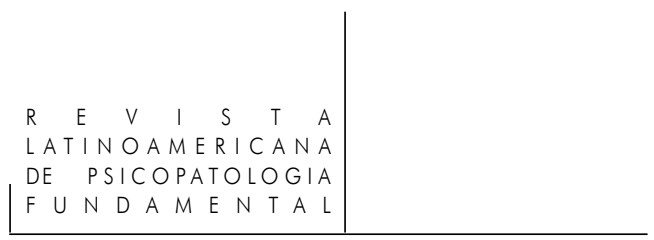

memorativa, e uma memória que pertence à alma sensitiva. Esta última faz tornar a sentir o que já se sentiu, sem que a razão seja capaz de dar significado:

(...) d'alg?as cousas tristes havemos lembramento que nom recebemos alg?u sentido, a qual lembrança me parece, principalmente, aa cabeça perteencer. E aquela medês, per vista de pessoas, ouvir de palavras, trespassa ao coraçom como se o feito rezente fosse, quando el se nembra e o sentia. (Dom Duarte, 1438?, p. 19)

Dom Duarte examina como pessoas queridas do passado e não mais presentes, além de tempos e lugares a elas de alguma forma relacionados, podem ser lembrados, por meio da imaginação, conversas, cantigas ou cheiros, reanimando o desejo de desfrutar de sua presença mais uma vez, ao que se dá o nome de saudade. Não há, portanto, saudade sem memória.

De fato, quatro séculos depois, como aponta Hannes Stubbe (1987), “divertir da memória" o objeto que pode produzir sofrimento na vontade é o primeiro dos três remédios para a saudade propostos pelo frei Mateus da Encarnação Pinna (1687-1764), em seu Viridiário Evangélico (1739). Ainda segundo o historiador da psicologia, os outros remédios para a saudade, prescritos pelo frei Pinna, consistem em suspender os discursos do entendimento e desafogar as penas por meio das lágrimas.

Outros autores afirmam que essa potência da alma teria não apenas o poder de deslocar e reanimar afetos, mas também de apoiar-se neles para seu retorno ao esquecido. Como bem expressa Baldassare Pisanelli, em seu Dell'anima, a memória pode, em suas palavras: "com um particular afeto de alegria ou de dor transportar-se na coisa que se deve recordar" (Pisanelli, 1594, p. 27, trad. nossa).

Essa capacidade específica da memória esclarece melhor, do ponto de vista da psicologia, a sua relação com a dor e, por conseguinte, com a própria consolação. Tomás de Aquino (1228-1274) na Suma Teológica já admitia que a memória pudesse evocar a dor, o que, inclusive, distingue a dor da alma, paixão da tristeza que pode se referir ao pretérito, da dor do corpo, sensação que depende da mediação corporal no presente.

$\mathrm{Na}$ lógica da psicologia aristotélico-tomista, não se desvencilhar da dor ou mesmo alimentá-la podia ser o efeito de manter a chamada espécie presente, conservando-a de algum modo na memória. O problema do melancólico, por exemplo, é que ele confunde a espécie com a coisa ou a pessoa perdida, eternizando o luto numa tentativa ilusória de não perdê-la. O melancólico é incapaz de esquecer e, assim, perpetua a dor do momento da perda.

Em particular, a perda de um grande amor não se esquece facilmente. Ou, como afirma padre Antônio Vieira:

Porém, quando o tempo, que é a Hema de todas as dores, a não digere, não pode haver maior, nem mais provado argumento, tanto da grandeza da dor, como

Rev. Latinoam. Psicopat. Fund., São Paulo, v. 14, n. 4, p. 711-720, dezembro 2011 
da grandeza do coração, que a não digeriu. Grande dor em grande coração, não a digere o tempo. (Vieira, 1684, p. 487)

Com efeito, dentre os remédios ao amor propostos por Ovídio (43 a.C.-17), referência incontornável nos discursos sobre as vicissitudes amorosas produzidos na Idade moderna, está evitar tudo que possa trazer à lembrança a pessoa amada. Sempre em seu Os remédios do amor, o poeta latino aconselha, em específico, queimar as cartas de amor, pois mesmo as almas firmes são abaladas pela sua leitura; afastar-se dos retratos, para não se consumir diante de uma imagem muda e evitar todos os lugares que foram o teatro dos encontros, que teriam o poder de causar a dor. Entretanto, Ovídio não deixa de descrever o expediente de se também usar da memória para superar uma paixão amorosa quando, por exemplo, sugere pensar nos tormentos sofridos na sua companhia para se esquecer alguém.

Enfim, o distanciamento da dor poderia ocorrer espontaneamente, mas, sobretudo, por obra ativa do consolado. Esse último empreende uma dinâmica de desligamento e superação da dor e reorganização afetiva perante a realidade presente. O enlutado deveria, amparado pelo logos e instrumentado pela memória, deslocar-se da morte e da perda e voltar-se para a vida. Para tanto, é necessário uma dinâmica sutil entre lembrar e esquecer, na qual, porém, corre-se o risco de intensificar ainda mais a dor.

Havia, inclusive, quem admitisse um caráter incontrolável na própria memória, que ora não deixa esquecer o mal, ora falha quando mais se precisa dela. Baltasar Gracián (1601-1658), em seu Oráculo manual e arte da prudência (1647), afirma que saber esquecer é mais ventura do que arte:

As coisas que mais devem ser esquecidas são as mais lembradas; a memória não só é vilã para faltar quando é mais necessária como também é néscia para acudir quando não convém: no que causa pena é prolixa, no que haveria de dar gosto é descuidada. Às vezes o remédio do mal consiste em esquecê-lo, e esquece-se o remédio; convém, pois, afazê-la a tão cômodos costumes, porque só ela basta para dar felicidade ou inferno. (CCLXII, p. 151)

Uma vez que se trata aqui de uma questão de memória, vale lembrar que obras do jesuíta aragonês Gracián tinham seu lugar na biblioteca de Lacan. De qualquer modo, essa noção de memória fora do controle da consciência, fugidia e suficiente para causar o paraíso ou o inferno parece mais compatível com a ideia de um inconsciente e, portanto, nos remete novamente à psicanálise, o que sinaliza, mais uma vez, sua relação, profunda e ainda tão ignorada, com a antiga tradição da medicina da alma. Ou, como afirma o próprio Lacan (1960):

Não reconhecer a filiação ou a paternidade cultural que há entre Freud e uma certa virada do pensamento, manifesta neste ponto de fratura que se situa por

Rev. Latinoam. Psicopat. Fund., São Paulo, v. 14, n. 4, p. 711-720, dezembro 2011 


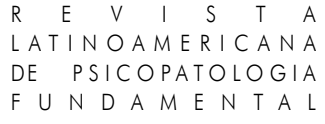

volta do início do século XVI, mas que prolonga poderosamente suas ondas até o fim do século XVII, equivale a desconhecer completamente que tipo de problemas se endereça a interrogação freudiana. (p. 117)

\section{Referências}

Aristóteles. Petit traités d'histoire naturelle (Parva Naturalia). Ed. bilingue de R. Mugnier. Paris: Les Belles Lettres, 2002.

BERLinck, M. T. Morte sem futuro e morte com futuro. A questão do tempo na morte. Revista Latinoamericana de Psicopatologia Fundamental, v. 14, n. 3, p. 419-425, set.2011.

BoÉcio. A consolação da filosofia. São Paulo: Martins Fontes, 1998.

Carruthers, M. J. The book of memory. A study of memory in Medieval culture. Cambridge: Cambridge University Press, 1990.

Chiecchi, G. La parola del dolore. Primi studi sulla letteratura consolatoria tra medioevo e umanesimo. Roma/Padova: Editrice Antenore, 2005.

718 Dom Duarte (1438?). Leal Conselheiro. Edição crítica, introdução e notas de M. H. L. Castro. Lisboa: Imprensa Nacional - Casa da Moeda, 1998.

Eckhart, M. O livro da divina consolação e outros textos seletos. Trad. brasileira de Fr. R. Vier [et al.]. Bragança Paulista: Editora Universitária São Francisco, 2006.

Freud, S. (1917). Luto e melancolia. In: Obras Completas. Trad. de P. C. de Souza. São Paulo: Companhia das Letras, 2010. V. 12.

. (1926). Hemmung, Sympton und Angst. In: Gesammelte Werke. Frankfurt am Main: Fischer Verlag, 1976. V. XIV.

Giard, L. The Jesuit College. A Center for Knowledge, Art, and Faith 1548-1773. Studies in the Spirituality of the Jesuits, n. 40/1, 2008.

Gracián, B. (1647). A arte da prudência. Tradução brasileira de I.C. Benedetti. São Paulo: Martins Fontes, 1996.

Lacan, J. (1960). Le séminaire. Livre VII. L'éthique de la Psychanalyse. Paris: Seuil, 1986.

Massimi, M. A memória ventre da alma. Revista Latinoamericana de Psicopatologia Fundamental, v. 13, n. 4, p. 667-679, dez.2010.

OvíDio. L'Art d'aimer. Les Remèdes à l'amour. Les produits de beauté pour le visage de la femme. Trad. francesa de H. Bornecque. Paris: Gallimard, 2007.

Pisanelli, B. Dell'anima. Libri due. Venetia: Roberto Meietti, 1594. 
Plutarco. Consolation à Apollonios. Trad. Francesa de N. Waquet. Paris: Éditions Payot \& Rivages, 2008.

Moralia. Cambridge, Massachusetts: Harvard University Press, 1961.

SÊNECA. Entretiens. Lettres a Lucilius. Introdução e tradução de Paul Veyne. Paris: Robert Lafond, 1998.

. Consolação a Márcia. Revista Latinoamericana de Psicopatologia Fundamental, v. 10, n. 1, p. 156-181, mar.2007.

Stubвe, H. Geschichte der Psychologie in Brasilien. Von den Indianischen und afrobrasilianischen Kulturen bis in die Gegenwart. Berlin: Dietrich Reimer Verlag, 1987.

Stucchi, S. (Org.). Antiche Consolazioni. Milano: Edizioni Medusa, 2007.

Tomás de Aquino. Suma Teológica. Edição bilingue. São Paulo: Loyola, 2003.

VieirA, A. (1684). Sermões. Org. de A. Pécora. Tomo 2. São Paulo: Hedra, 2001.

(Remembering to forget: the memory of pain in mourning and consoling)

This article discusses sources for the ancient tradition of consoling and other variations of the medicine of the soul, in order to examine the specific dimension of memory during mourning. In particular, the author analyses how memory was defined and, especially, its relationships to the origin and permanence of the pain of the soul. Finally, therefore, the functions of memory in early modern therapeutic practices are discussed.

Key words: Memory, pain of the soul, mourning, consoling, psychoanalysis

(Se rappeler pour oublier: la mémoire de la douleur dans le deuil et dans la consolation)

Cet article reprend des discours de l'ancienne tradition de la consolation ainsi que d'autres variations de la médecine de l'âme pour examiner la dimension de la mémoire dans le travail du deuil. Plus précisément, on analyse comment la mémoire était conçue et, surtout, son rapport avec l'origine et la permanence des douleurs de l'âme et, par conséquence, sa fonction dans les pratiques thérapeutiques de la première modernité.

Mots clés: Mémoire, douleurs de l'âme, deuil, consolation, psychanalyse 
(Recordar para olvidar: la memória en el dolor del duelo y en la consolación)

Este artículo retoma los discursos de la antigua tradición de la consolación y de otras variantes de la medicina del alma para examinar la dimensión de la memoria, especificamente durante el trabajo de duelo. De manera particular se analisa cómo la memoria era definida, principalmente, cuál era su relación con el origen y permanencia de los dolores del alma y consequentemente, cuál era su función en las prácticas terapéuticas en la primera modernidad.

Palabras clave: Memoria, males del alma, duelo, consolación, psicoanálisis

Citação/Citation: SILVA, P.J.C. Lembrar para esquecer: a memória da dor no luto e na consolação. Revista Latinoamericana de Psicopatologia Fundamental, São Paulo, v. 14, n. 4, p. 711-720 , dez.2011.

Editor do artigo/Editor: Prof. Dr. Paulo José Carvalho da Silva

Recebido/Received: 3.11.2011/11.3.2011 Aceito/Accepted: 8.11.2011/11.8.2011

Copyright: (C) 2009 Associação Universitária de Pesquisa em Psicopatologia Fundamental/ University Association for Research in Fundamental Psychopathology. Este é um artigo de livre acesso, que permite uso irrestrito, distribuição e reprodução em qualquer meio, desde que o autor e a fonte sejam citados/This is an open-access article, which permits unrestricted use, distribution, and reproduction in any medium, provided the original author and source are credited.

Financiamento/Funding: Esta pesquisa é financiada pelo Conselho Nacional de Desenvolvimento Científico e Tecnológico - CNPq/This research is funded by National Counsel of Technological and Scientific Development - CNPq.

Conflito de interesses/Conflict of interest: $\mathrm{O}$ autor declara que não há conflito de interesses/The author declares that has no conflict of interest.

\section{Paulo José Carvalho da Silva}

Psicólogo, psicanalista, mestre em História da Ciência pela Pontifícia Universidade Católica de São Paulo - PUC-SP (São Paulo, SP, Br); doutor em Psicologia pela Universidade de São Paulo - USP (São Paulo, SP, Br); professor doutor da Faculdade de Psicologia da PUC-SP (São Paulo, SP, Br); membro da Associação Universitária de Pesquisa em Psicopatologia Fundamental (São Paulo, SP, Br).

Rua Cajaíba, 15

05025-000 São Paulo, SP, Brasil

Fone: (11) 9248-9202

e-mail:paulojcs@hotmail.com 